\title{
Symptomatic Coronary-Pulmonary Fistula Revealed with Coronary CT Angiography
}

\author{
Sára Papp, István Ferenc Édes, Béla Merkely, Pál Maurovich-Horvat, Mihály Károlyi \\ MTA-SE Cardiovascular Imaging Research Group, Heart and Vascular Center, Semmelweis University, Budapest, Hungary
}

\section{ABSTRACT}

Introduction: Coronary artery fistulas are usually incidental findings and rarely cause any clinical symptoms. Case presentation: In this case a coronary pulmonary fistula was revealed by coronary CT angiography and as it was considered responsible for the patients' symptoms, its' closure was performed during percutaneous coronary intervention. Conclusion: The noninvasive coronary CT angiography is a valuable examination in the diagnosis of coronary anomalies.

Keywords: coronary CTA, invasive coronary angiography, coronary artery fistula, atypical chest pain

\section{ARTICLE HISTORY}

Received: May 15, 2017

Accepted: June 26, 2017

\section{CORRESPONDENCE}

Pál Maurovich-Horvat

Határôr u. 18

H-1122 Budapest, Hungary

Tel: +36206632485

Fax: +3614586842

E-mail: p.maurovich.horvat@mail. harvard.edu

\section{INTRODUCTION}

Coronary artery fistulas (CAF) are abnormal connections between the coronary artery system and cardiac chambers or thoracic vascular structures. Most patients with CAF are asymptomatic, and fistulas are typically found incidentally during imaging studies. However, in some cases CAFs may cause serious conditions for the patient, such as myocardial ischemia, right heart failure, arrhythmias, or even sudden death, therefore is important to make the correct diagnosis.

\section{CASE PRESENTATION}

A 64-year-old man was scheduled for coronary CT angiography (CTA) due to atypical chest pain and intermediate cardiovascular risk. Coronary CTA identified a partially calcified plaque with high-risk features (low attenuation, positive remodeling, and napkin-ring sign) causing severe $(70 \%)$ luminal stenosis in the mid segment of the left anterior descending (LAD) coronary artery. Additionally, several small tortuous branches were visualized connecting the septal branch of the LAD with the pulmonary artery (Figure 1).

The patient underwent invasive coronary angiography (ICA), which confirmed a coronary fistula between the LAD-septal branch and the pulmonary trunk (Figure 2). Fractional flow reserve (FFR) measurement was performed, which verified the significant stenosis in the mid LAD segment. Accordingly, percutaneous coronary intervention (PCI) was performed with a drug-eluting stent. Post-PCI FFR value was normal; however, after nitroglycerine administration, a significant decrease in the FFR 


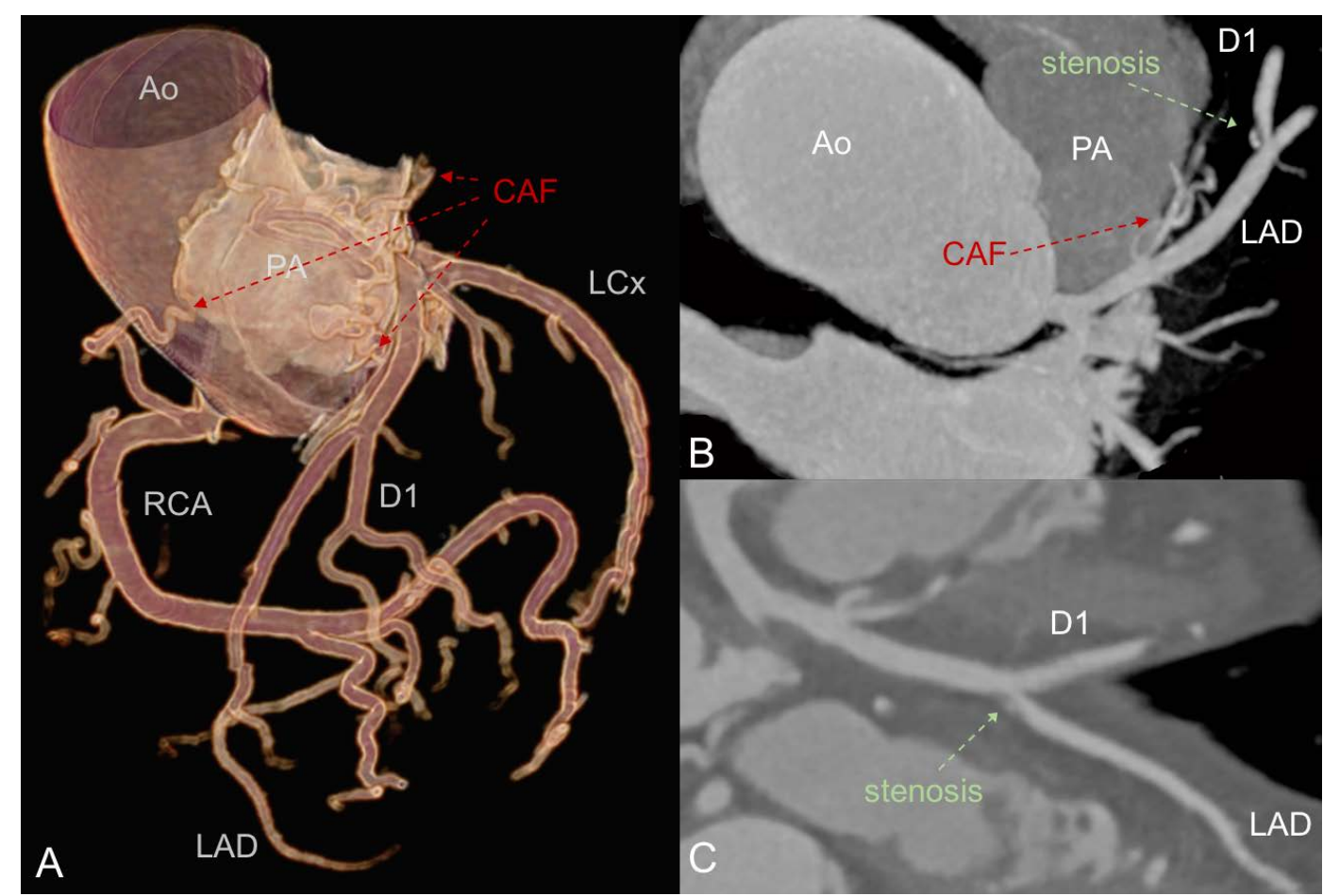

FIGURE 1. Coronary CT angiography. A - 3D volume rendered image of the coronary tree. Red arrows indicate the coronary artery fistula connecting the first septal branch of the LAD to the pulmonary trunk. B, C - Coronary CTA images with multiplanar reconstruction. On Panel B small branches, susceptible for coronary fistula can be seen (red arrow). Panel C illustrates a high-grade stenotic, partially calcified plaque in the mid LAD segment (green arrow).

value was observed, presumably associated with the dilatation of the fistula. Therefore, coil embolization of the fistula was performed (Figure 3). The FFR value normalized, and the patient became asymptomatic.

Twelve months later, due to the reoccurrence of his symptoms, the patient underwent control ICA, which ex- cluded any significant restenosis in the mid LAD stent. However, the complete reopening of the coronary fistula was detected. A second attempt for the coil embolization was made; however, due to embolization of the coil during deployment in the LAD-septal branch, it partially shifted into the LAD. Consequently, a coronary artery stent was

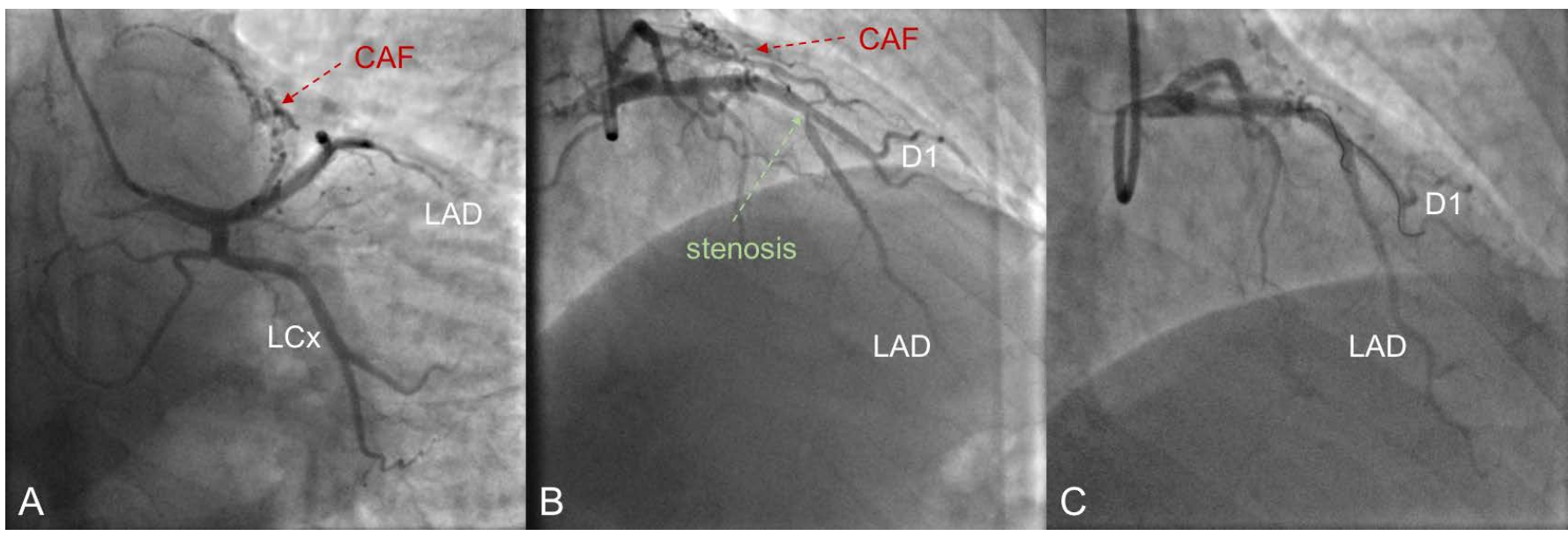

FIGURE 2. Invasive coronary angiography and percutaneous coronary intervention. A shows the coronary artery fistula (red arrow) originating from the first septal branch of the LAD. B illustrates the significant stenosis in the LAD-diagonal branch bifurcation (green arrow). C - Restored lumen of the LAD after stent implantation. 


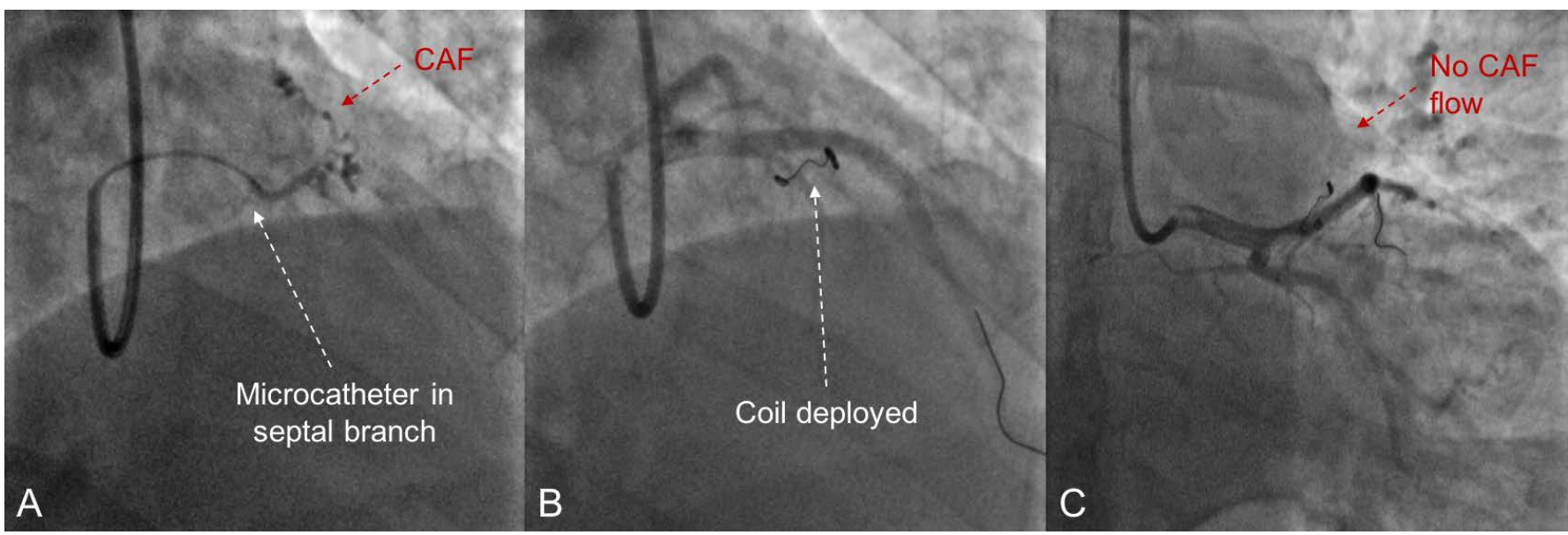

FIGURE 3. Coil embolization of the coronary fistula. A - Microcatheter placement in the septal branch of the LAD; B - Coil placement in the coronary fistula; $\mathbf{C}$ - No flow is present in the coronary-pulmonary fistula after successful coil embolization.

placed in the LAD to fix the coil position and prevent the occlusion of the LAD lumen. The stent deposition was successful, and no refill of the CAF was observed. Optical coherence tomography (OCT) imaging was performed, which confirmed the good positioning of the LAD stent (Figure 4). The patient was discharged symptomless after the procedure.

The patient agreed to the publication of his data, and the institution where the patient had been admitted approved the publication of the case.

\section{DISCUSSION}

Coronary artery fistulas (CAF) are direct precapillary communications between the coronary arteries, cardiac chambers, or other vessels. ${ }^{1-4}$ CAFs can originate from the left and right coronary system, and the most common termination sites are the right ventricle, right atrium, and the pulmonary artery. ${ }^{2,3}$ CAFs usually have small calibers and do not have any hemodynamic impact., ${ }^{2,3}$ Rarely, large fistulas may cause symptoms and serious conditions for the patient. ${ }^{3}$ Invasive coronary angiography is the method of choice to identify coronary fistulas. However, due to the increasing number of coronary CT angiography used on patients with chest pain, CAFs and other coronary anomalies are more frequently diagnosed. ${ }^{2}$ Spontaneous closure of these fistulas may happen, but surgical or transcatheter closure of the CAF may also be indicated in symptomatic patients with large, hemodynamically significant fistulas. ${ }^{4,5}$
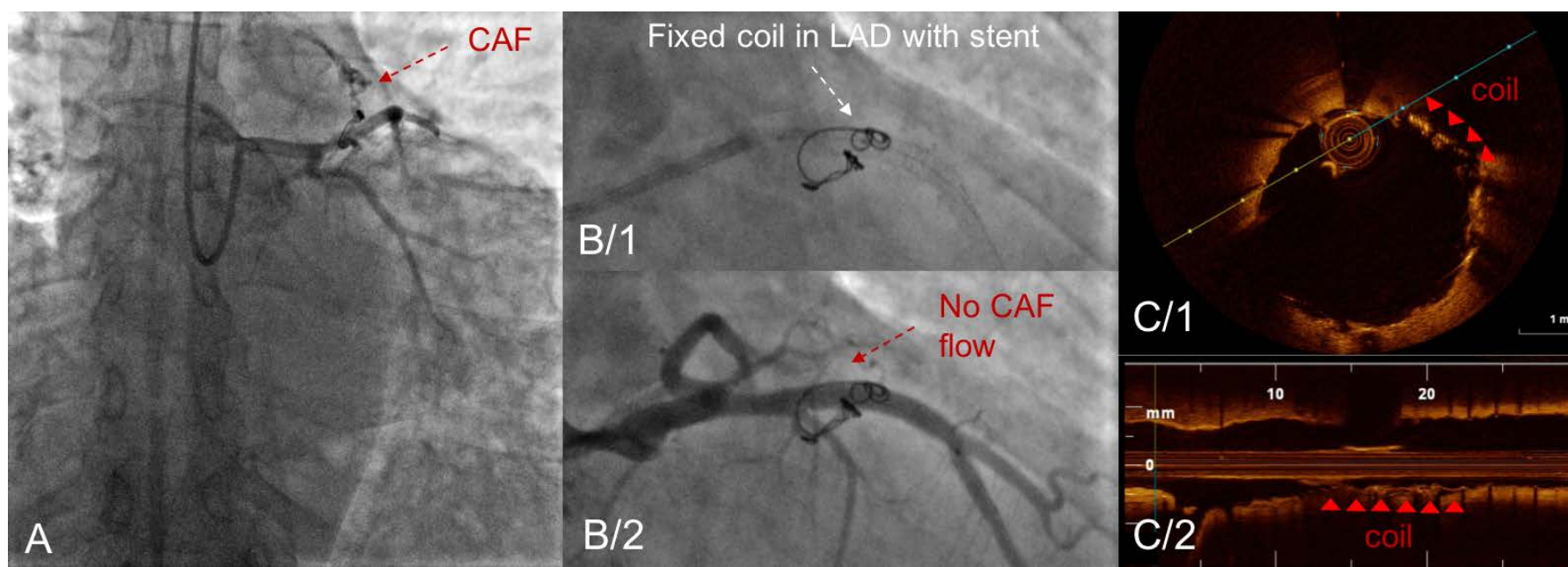

FIGURE 4. Second coronary angiography due to reoccurrence of patients' symptoms. A - Reopened coronary fistula (red arrow). B/1 - Coil stabilization with a coronary stent in the LAD; $\mathbf{B} / \mathbf{2}$ - Complete coronary flow in the LAD with no refill of the fistula after coil embolization; $\mathbf{C} / \mathbf{1}$-Cross-sectional OCT image of the coil in the LAD (red arrows); $\mathbf{C} / \mathbf{2}$-Longitudinal OCT image of the LAD (red arrows indicate the coil). 


\section{CONCLUSION}

Our case underlines the potential of noninvasive coronary CTA to detect not only significant coronary luminal stenosis, but also extracoronary findings, such as fistulas as an underlying cause for patients' chest pain.

\section{CONFLICT OF INTEREST}

None declared.

\section{ABBREVIATIONS}

CAF coronary artery fistula

CTA computed tomography angiography

FFR fractional flow reserve

ICA invasive coronary angiography

LAD left anterior descending coronary artery

LCx left circumflex coronary artery

оCT optical coherence tomography
PCI percutaneous coronary intervention

RCA right coronary artery

\section{REFERENCES}

1. Maurovich-Horvat P, Ferencik M, Voros S, Merkely B, Hoffmann U. Comprehensive plaque assessment by coronary CT angiography. Nat Rev Cardiol. 2014;11:390-402. doi: 10.1038/nrcardio.2014.60.

2. Zenooz NA, Habibi R, Mammen L, Finn JP, Gilkeson RC. Coronary Artery Fistulas: CT Findings. RadioGraphics. 2009;29:781-789. https://doi.org/10.1148/rg.293085120.

3. Said SAM, Thiadens AAHJ, Fieren MJCH, Meijboom EJ,van der Werf T, Bennink GBWE. Coronary artery fistulas. Neth Heart J. 2002;10:65-78.

4. Natarajan A, Khokhar AA, Kirk P, Patel HH, Turner D. Coronary-pulmonary artery fistula: value of $64-\mathrm{MDCT}$ imaging. QJ Med. 2013;106:91-92. doi: 10.1093/qjmed/hcr254.

5. Armsby LR, Keane JF, Sherwood MC, Forbess JM, Perry SB, Lock JE. Management of coronary artery fistulae. Patient selection and results of transcatheter closure. J Am Coll Cardiol. 2002;39:1026-1032. 